\title{
Souvenir du P. Moses Nagy
}

\author{
Sergio Villani \\ University York
}

$\mathbf{P}_{\text {our tous les membres de la Société Paul Claudel }}$ d'Amérique, le père Nagy demeure l'image d'un collègue enthousiaste et admirablement infatigable. Pendant une trentaine d'années il dirige Claudel Studies, souvent dans des conditions peu favorables. La longévité connue de cette revue est due largement aux grands efforts du P. Nagy. Son dévouement à l'œuvre claudélienne est sans égal. Nous chérissons aussi ses communications faites au sein de l'association Modern Language. Il y apportait non seulement ses vastes connaissances et sa verve discursive mais aussi une large dose de bonhomie. Curé de foi profonde, mais peu ascète, il pouvait nous diriger aussi vers les bons restaurants que ce soit à New York, à Chicago ou à San Francisco, et signaler leurs bons vins... Ayant connu nos familles, il ne manqua jamais de demander des nouvelles et d'envoyer ses salutations. Peu d'entre nous, cependant, connaissent les aspects de sa vie après la " retraite » et son retour en Hongrie, son pays natal. À vrai dire, il y trouve peu de repos et de paix, mais des responsabilités multiples et onéreuses auxquelles il se plie sans trop se plaindre. En plus, malgré des ennuis de santé, il contemple même organiser en 1998, à Székesfehérvàr, un colloque international sur l'œuvre de Claudel, un projet qu'il ne réalise pas, faute de moyens financiers et de sa santé de plus en plus fragile. Je relis avec une émotion vive une lettre qu'il m'adresse en février 1999, où il décrit sa vie en Hongrie. On y reconnaît l'homme de foi, de lettres, d'esprit et de grand cœur :

Pour mettre fin à mon silence interminable, je vais vous faire compte rendu de ce qui ce passe dans cette ville qui, 


\section{Sergio Villani}

comme la plupart des villes de Hongrie, se cache sous une couche épaisse de neige laquelle a cessé de tomber voilà quelques jours. Mes amis me disent que ce n'est pas la neige qui les effraie; ce sera plutôt le moment où la neige commencera à fondre. Cela dit, la neige qui avait ralenti la circulation des trains et des autobus aurait d̂u suffire pour que nos étudiants restent sur place pendant la fin de semaine, mais qui aurait pu retenir les jeunes filles et les garçons de nos collèges?! Vendredi après-midi (le 12 février), une fois qu'ils purent sortir de classe, c'était la révolte, la débandade, la fuite : "mes» jeunes filles partaient comme si ç'avait été la menace $d u$ Vésuve. Finalement une quinzaine d'entre elles sont restées; le reste? On ne les a pas vues pendant plusieurs jours. Il va sans dire que depuis que je suis arrivé ici à Eger, j'ai tout fait pour m'habituer à la situation, vie, mentalité, etc. $Y$ ai-je réussi? Étant donné que j'ai trois postes à remplir, je me demande si j'ai bien réussi. Si on m'avait dit il y a deux ans qu'à mon âge de 72 ans je serais nommé "curé" (car enfin je suis une sorte de curé), nommé directeur d'un collège de jeunes filles, et nommé encore membre du Conseil des Directeurs d'un grand lycée, je n'aurais pas cru à mes oreilles... Et cependant, ce n'est pas tout, car je me suis relancé dans l'enseignement : je vais enseigner la religion EN ANGLAIS. Oui, le lycée s'est engagé dans un programme exotique d'anglais : il y a moyen de passer le baccalauréat EN ANGLAIS en trois sujets : géographie, religion et civilisation (américaine). Voilà comment j'enrichis mes activités quotidiennes, car (entre nous) peu de professeurs sauraient enseigner EN ANGLAIS la religion en Hongrie. (merci pour l'auto-compliment!) Sachez, cependant, que la vie n'est pas si simple: il m'est arrivé déjà une fois de m'écrouler sous le poids du travail. (C'était certes à cause du travail!) Nous étions début décembre. Un soir je recevais un groupe de prêtres 
pour célébrer THANKSGIVING à l'américaine, avec la dinde farcie, etc. Eh bien, après les hors-d'œuvre, j'ai été saisi par un malaise inusité; j'ai d̂u me retirer, et le lendemain matin j'ai été hospitalisé, avec ulcère (compliqué d'hémorragie, VULGO : bleeding ulcers!). Et j'ai passé 12 jours à l'hôpital d'où je suis sorti le 16 décembre. Bien sûr, cela ne m'a pas empêché de partir pour San Francisco, le 26 décembre, où j'avais une communication à faire sur "Les sources baroques du Soulier de satin de Claudel. "Et je suis rentré en Hongrie le 7 janvier, en grande forme. Ici, entre parenthèses, je vais vous réveler un secret : je pense qu'avec cette communication j'aurais terminé mes recherches et mes conférences. (Même sur Claudel!). Mais il ne faut pas avoir peur que je reste inactif! Au contraire, mes activités d'à présent me présentent tellement de " distractions" qu'il m'est impossible de me concentrer, lire, ou écrire. Je voudrais espérer, cependant, trouver un peu de temps pendant les vacances d'été pour me déplacer vers la France, vers l'Ouest. Mais avec la paroisse sur le dos, on ne bouge pas facilement, étant donné qu'il est difficile de trouver un remplaçant. Cela dit, rien ne m'empêchera de chercher des prétextes... Si vous voyez en août un vieux prêtre flâner dans Paris, ce sera moi. Tout cela pourrait arriver à Toronto ou à Montréal aussi...

Le P. Moses Nagy : claudélien, professeur, fidèle serviteur de Notre Seigneur.

\section{Requiescat in pace.}

